\title{
Effects of Heating Rate on Formation of Globular and Acicular Austenite during Reversion from Martensite
}

\author{
Xianguang Zhang ${ }^{1, *}$, Goro Miyamoto ${ }^{2}$, Yuki Toji ${ }^{3}$ and Tadashi Furuhara ${ }^{2}$ \\ 1 School of Metallurgical and Ecological Engineering, University of Science and Technology Beijing (USTB), \\ Beijing 100083, China \\ 2 Institute for Materials Research, Tohoku University, 2-1-1 Katahira, Aoba-ku, Sendai 980-8577, Japan; \\ miyamoto@imr.tohoku.ac.jp (G.M.); furuhara@imr.tohoku.ac.jp (T.F.) \\ 3 Steel Research Laboratory, JFE Steel Corporation, 1 Kawasaki-cho, Chuo-ku, Chiba 260-0835, Japan; \\ y-toji@jfe-steel.co.jp \\ * Correspondence: xgzhang@ustb.edu.cn; Tel.: +86-10-6233-2267
}

Received: 29 January 2019; Accepted: 20 February 2019; Published: 24 February 2019

\begin{abstract}
The effects of heating rate on the formation of acicular and globular austenite during reversion from martensite in Fe-2Mn-1.5Si-0.3C alloy have been investigated. It was found that a low heating rate enhanced the formation of acicular austenite, while a high heating rate favored the formation of globular austenite. The growth of acicular $\gamma$ was accompanied by the partitioning of $\mathrm{Mn}$ and $\mathrm{Si}$, while the growth of globular $\gamma$ was partitionless. DICTRA simulation revealed that there was a transition in growth mode from partitioning to partitionless for the globular austenite with an increase in temperature at high heating rate. High heating rates promoted a reversion that occurred at high temperatures, which made the partitionless growth of globular austenite occur more easily. On the other hand, the severer Mn enrichment into austenite at low heating rate caused Mn depletion in the martensite matrix, which decelerated the reversion kinetics in the later stage and suppressed the formation of globular austenite.
\end{abstract}

Keywords: austenite reversion; heating rate; morphology; kinetics; interface mobility

\section{Introduction}

Coarse polygonal ferrite and retained austenite $(\gamma)$ in conventional transformation-induced plasticity (TRIP)-assisted steels were replaced by fine lath-type morphologies of the annealed martensite matrix and retained $\gamma$ to improve the stretch-flangeability [1]. These fine lath-type morphologies can be generated by starting with martensite as the initial structure for the reversion treatment and subsequent austempering process [1]. The mechanical properties of TRIP steel depend largely on the phase fraction and stability of the retained $\gamma$, which are strongly influenced by the transformation kinetics and elements' partitioning behavior during the $\gamma$ reversion.

In $\gamma$ reversion from lath martensite, two types of reverted $\gamma$ (acicular and globular $\gamma$ ) can be formed [2-16]. These two types of $\gamma$ have different crystallographic characters and growth kinetics $[15,16]$. The acicular $\gamma$ grains hold near-Kurdjumov-Sachs (K-S) orientation relationships (OR) with all the surrounding tempered martensite (TM) $[4,10-12,15]$ and grow by migration of the $\alpha / \gamma$ interface with the near-K-S OR. The growth of acicular $\gamma$ is accompanied by Mn and Si partitioning during isothermal holding, regardless of reversion temperatures [16]. On the other hand, the globular $\gamma$ holds a near-K-S OR with a part of its surrounding TM variant, and growth is accompanied by Mn and Si partitioning at low temperatures and becomes partitionless at high temperatures [15,16].

The reversion of $\gamma$ during isothermal holding has been well studied in previous works $[10,16,17]$. However, in the industry, steels are usually continuously heated. The continuous heating process is 
more complex than that of the isothermal holding process due to the change in annealing temperature with time. Heating rate is an important parameter in the continuous heating process, which has a strong influence on the microstructure of the reverted $\gamma$ in low-alloy steels. Matsuda et al. [4] and Kimmins et al. [7] reported that raising the heating rate increased the degree of grain refinement by forming a higher proportion of globular $\gamma$ in low-carbon low-alloy steels. Meanwhile, Sadovskii [3] found that it was possible to reconstitute the exact original prior $\gamma$ grains through the coalescence of the acicular $\gamma$ at rapid or slow heating rates, but not at intermediate heating rates. However, the mechanisms for the effects of heating rate on the formation of the acicular and globular $\gamma$ remain unclear. The present study has been undertaken to systematically study the microstructure evolution and element partitioning behavior during continuous heating at various heating rates and aims to clarify the effects of heating rate on the reversion mechanisms.

The current results clearly showed that a change from acicular to globular morphology was observed, experimentally, from low to high heating rates, accompanied by a change from a partitioning to partitionless mechanism of the substitutional elements. This important finding can help in the design of heat treatments of new-generation TRIP steels, for example, to control the morphologies and element partitioning behavior during reversion through controlling the heating rate.

\section{Materials and Methods}

The chemical composition of the alloy used in this study is shown in Table 1. The ortho-equilibrium $\mathrm{A}_{\mathrm{e} 1}$ and $\mathrm{A}_{\mathrm{e} 3}$ temperatures calculated by ThermoCalc 4.0 using the TCFE7 database are 965 and $1074 \mathrm{~K}$, respectively. The samples cut from a hot-rolled plate were homogenized at $1423 \mathrm{~K}$ in an Ar-filled silica tube for $24 \mathrm{~h}$. After the homogenizing treatments, no obvious segregation of the alloying element was detected by electron probe microanalysis. The homogenized samples were austenitized at $1323 \mathrm{~K}$ for $1.8 \mathrm{ks}$, and then quenched into ice brine to obtain full martensitic microstructures with prior $\gamma$ grain sizes of approximately $200 \mu \mathrm{m}$. Cylindrical specimens (3 mm diameter, $10 \mathrm{~mm}$ long) were subsequently machined for reversion treatment by using a dilatometer, where specimens were induction-heated at various heating rates in the range of $0.1-20 \mathrm{~K} / \mathrm{s}$ and quenched by He gas immediately after reaching various specified temperatures. After the heat treatments, the specimens were cut and mechanically polished with emery paper, diamond spray buff, and colloidal silica. Microstructures were characterized using optical microscopy (OM, Nikon Instech Co., Ltd., Tokyo, Japan) and field emission scanning electron microscopy (FE-SEM; JEOL, JSM-7001F, JEOL Ltd., Tokyo, Japan) after etching in a $2 \%$ Nital solution. Volume fractions of the overall, globular, and acicular $\gamma$ were quantified by point counting, and the details are described elsewhere [16]. The true thickness or true interspacing of acicular $\gamma$ were estimated to be a half of the apparent average thickness or interspacing measured by random line intersections on SEM images, to take a stereographic effect into account [18]. In addition, the local distributions of alloying elements were analyzed with field emission electron probe microanalyzer (FE-EPMA), operated at $15 \mathrm{kV}$ with the step size of $50 \mathrm{~nm}$.

Table 1. Chemical composition of the alloy used in this study (mass \%).

\begin{tabular}{cccccc}
\hline $\mathbf{C}$ & Si & Mn & P & S & Fe \\
\hline 0.30 & 1.49 & 2.02 & 0.006 & 0.002 & Bal. \\
\hline
\end{tabular}

\section{Results and Discussion}

\subsection{Reversion Kinetics and Element Partitioning Behavior during Continuous Heating}

The measured $A_{c 1}$ and $A_{c 3}$ temperatures ( $\alpha \rightarrow \gamma$ starting and finishing temperatures) against the heating rate is shown in Figure 1a, in which the equilibrium $A_{e 1}$ and $A_{e 3}$ temperatures were plotted for comparison. The $A_{c 1}$ temperature increased with an increase in heating rate, and the $A_{c 3}$ temperature 
decreased at first, and then it almost had no change regardless of the heating rate. Both the $A_{c 1}$ and $A_{c 3}$ temperatures were slightly above the equilibrium $A_{e 1}$ and $A_{e 3}$ temperatures.

The transformation kinetics obtained from the dilatometric analysis under different heating rates are displayed in Figure 1b. At low temperatures, the reverted $\gamma$ fraction was larger at a heating rate of $0.1 \mathrm{~K} / \mathrm{s}$ than that of the other two heating rates. This was due to the longer reversion time it experienced. However, at high temperatures, the $\gamma$ fraction decreased lower than that of the high heating rates. This dramatic change in reversion kinetics may strongly relate to the microstructures of the reverted $\gamma$ formed at different heating rates.
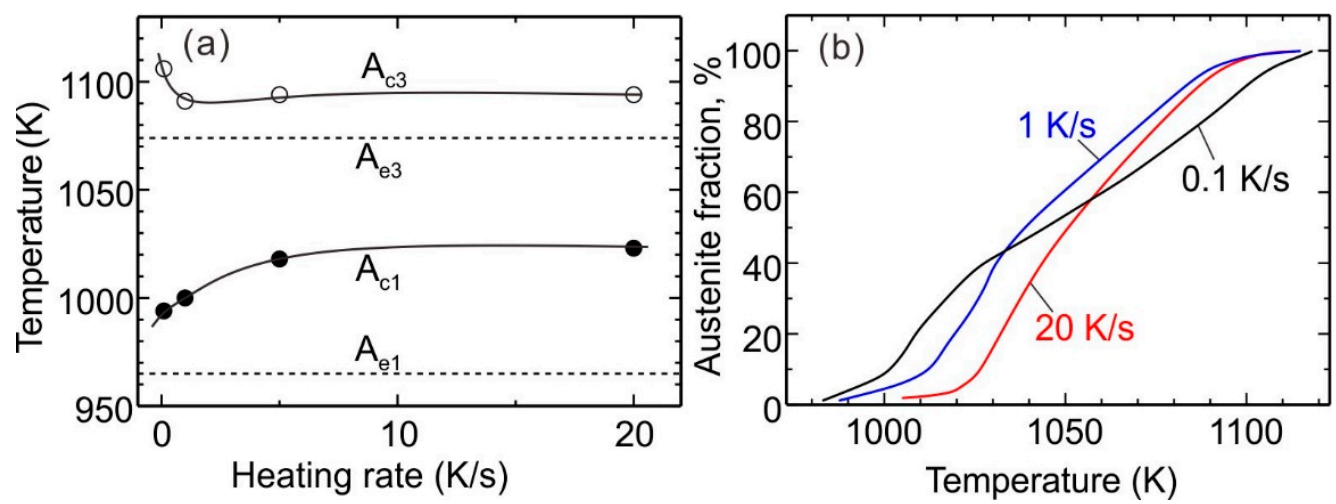

Figure 1. (a) The measured $A_{c 1}$ and $A_{c 3}$ temperatures as a function of heating rate, $(\mathbf{b}) \gamma$ reversion kinetics at different heating rates.

Figure 2a-h shows the OM and SEM images of the specimens quenched from $1073 \mathrm{~K}$ that were heated at different heating rates. At a heating rate of $0.1 \mathrm{~K} / \mathrm{s}$, a small amount of globular $\gamma$ grains (the white contrast, it is martensite at room temperature) were formed along the prior $\gamma$ grain boundaries, as shown in the OM image in Figure 2a. Meanwhile, the SEM image (Figure 2b) reveals that a large amount of acicular $\gamma$ (martensite at room temperature) grains was dominantly formed within the prior $\gamma$ grain, which was fine in appearance and hardly visible in the OM image in Figure 2a. By comparing the OM images of Figure $2 a, d, g$, it can be seen that the density of globular $\gamma$ grain clearly increased with the increase in heating rate. On the other hand, the amount of acicular $\gamma$ decreased and became thinner, as shown in the SEM images in Figure $2 b, e, h$.

Figure $2 \mathrm{c}, \mathrm{f}, \mathrm{i}$ quantitatively summarizes the volume fractions of the overall and the two morphologies of $\gamma$ against the temperature at these three heating rates. The solid circles and red diamonds respectively indicate the overall and globular $\gamma$ fractions, measured by point counting. For comparison, the $\gamma$ fractions that were evaluated from the dilatometric measurement and predicted by the ortho- and para-equilibrium (PE) models are also plotted. The overall $\gamma$ fractions measured by point counting were close to that of the dilatometric analysis, and they were lower than the ortho- and para-equilibrium predictions. From the kinetics curves, it is obvious that the fraction of globular $\gamma$ increased significantly with the increase in heating rate, while the inverse change occurred for that of the acicular $\gamma$. The larger size of the globular $\gamma$ compared with that of the acicular $\gamma$ suggests that the globular $\gamma$ grows faster than the acicular $\gamma$.

To understand the growth kinetics of the two morphologies of $\gamma$, the element partitioning behavior during reversion was examined by FE-EPMA analysis on the specimen that was quenched from $1073 \mathrm{~K}$ and heated at $1 \mathrm{~K} / \mathrm{s}$. The region for mapping is shown in Figure 3a, in which both the acicular and globular $\gamma$ coexist. The measured Mn and Si maps are shown in Figure 3b,c, respectively. It can be observed that Mn was enriched into acicular $\gamma$, while Si was enriched into tempered martensite (TM). This strongly indicates that the growth of acicular $\gamma$ was accompanied by the partitioning of $\mathrm{Mn}$ and $\mathrm{Si}$. 


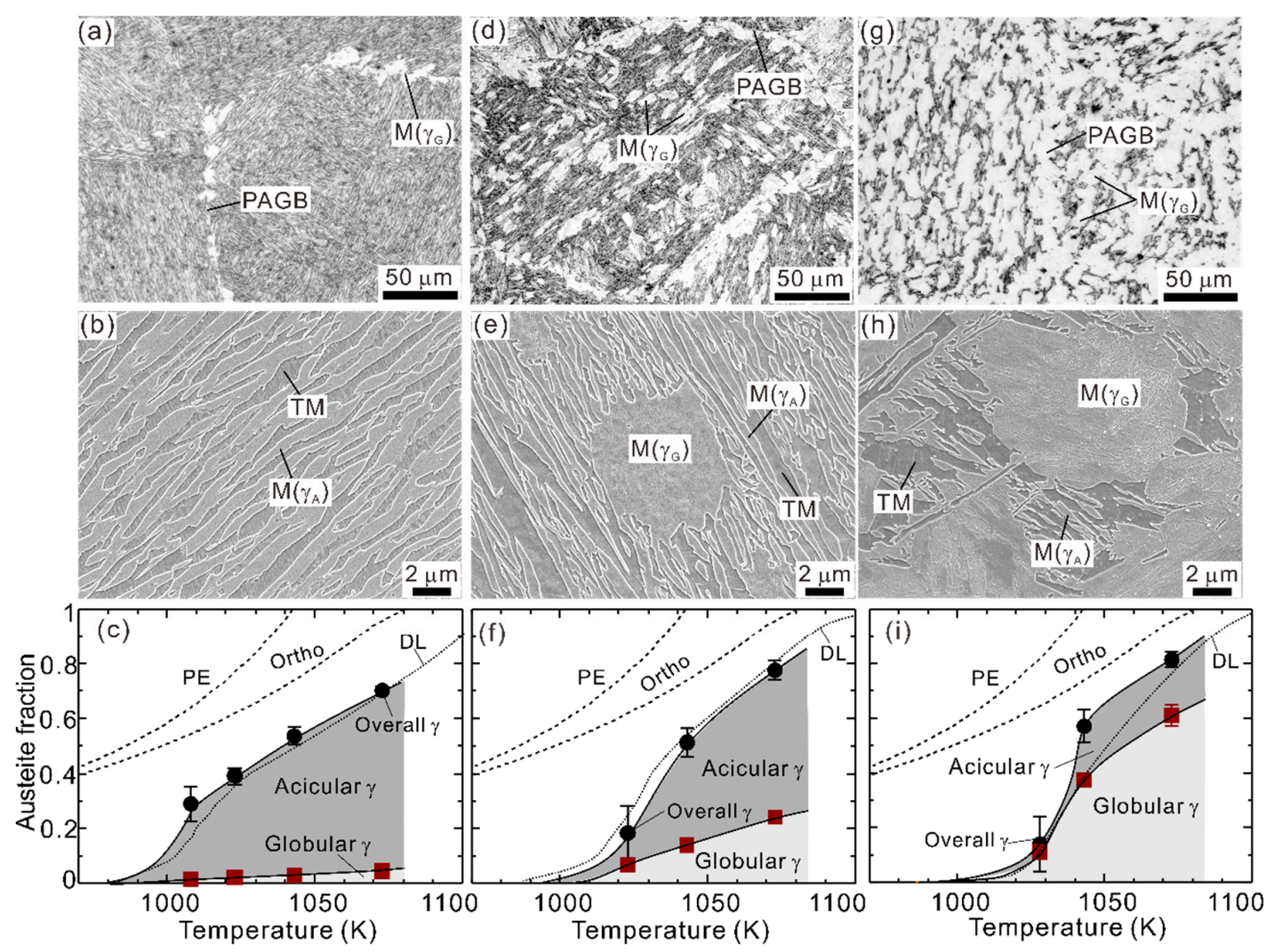

Figure 2. (a,d,g) Optical microscopy (OM) and (b,e,h) SEM images of the specimen quenched from $1073 \mathrm{~K}$ and heated at different heating rates: $(\mathbf{a}, \mathbf{b}) 0.1 \mathrm{~K} / \mathrm{s},(\mathbf{d}, \mathbf{e}) 1 \mathrm{~K} / \mathrm{s}$, and $(\mathbf{g}$,h) $20 \mathrm{~K} / \mathrm{s}$; temperature variation of the fractions of the overall, acicular, and globular $\gamma$ at heating rates of (c) $0.1 \mathrm{~K} / \mathrm{s}$, (f) $1 \mathrm{~K} / \mathrm{s}$, and (i) $20 \mathrm{~K} / \mathrm{s} . \gamma_{\mathrm{A}}(\mathrm{M})$ : acicular $\gamma$ (martensite at room temperature), $\gamma_{\mathrm{G}}(\mathrm{M})$ : globular $\gamma$, TM: tempered martensite.
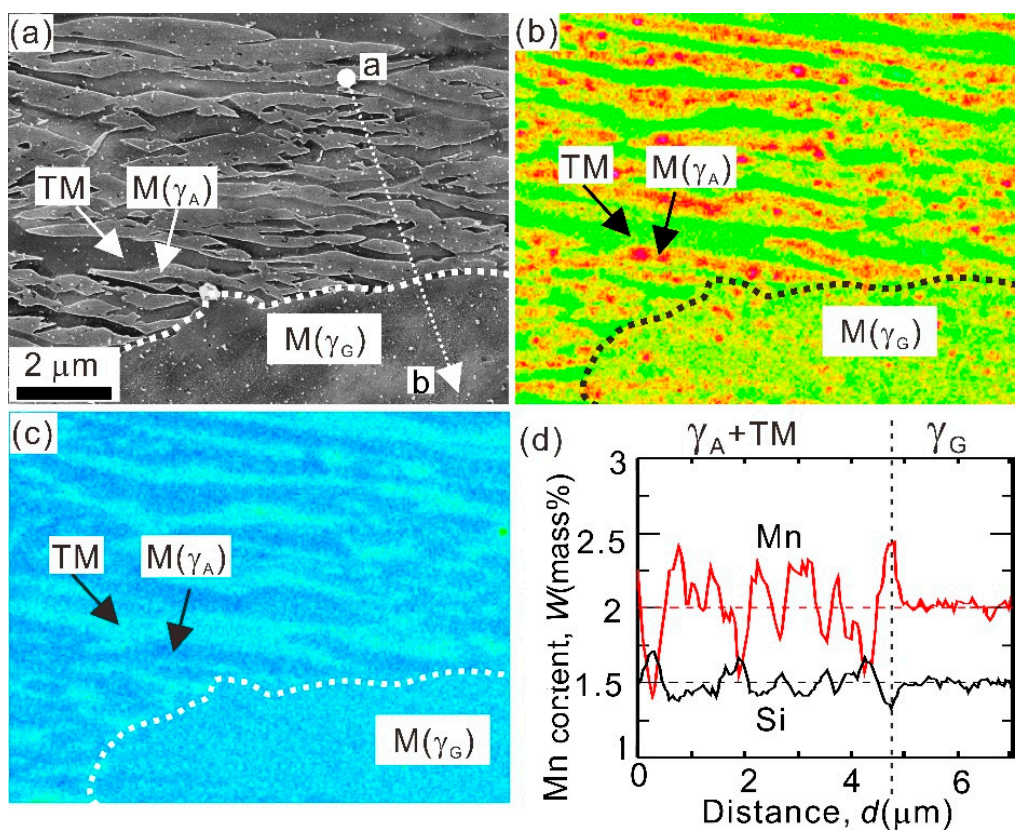

Figure 3. (a) SEM image of the specimen quenched from $1073 \mathrm{~K}$ heated at a rate of $1 \mathrm{~K} / \mathrm{s}$. EPMA maps of (b) Mn (c) Si taken from the same area as (a). (d) Mn and Si profiles along the dotted line $a b$ in (a). 
Meanwhile, from Figure 3b,c it seems that globular $\gamma$ had intermediate Mn and Si contents between the TM and acicular $\gamma$. The quantitatively measured Mn and Si contents along the line $a b$ in Figure 3a are shown in Figure 3d. It shows that the Mn and Si contents in the globular $\gamma$, located at the right-hand side of the graph, were closer to the bulk composition. This indicates that the growth of globular $\gamma$ and substitutional elements is partitionless, in contrast with the partitioning growth of acicular $\gamma$. This is consistent with the partitioning behavior of the elements during isothermal annealing at $1073 \mathrm{~K}[16]$.

\subsection{DICTRA Simulation of the Growth of Austenite}

To deeply understand the growth mode of the two types of $\gamma$ during continuous heating, the $\alpha / \gamma$ interface migration was simulated by DICTRA 4.0, which was used to simulate $\gamma$ growth kinetics during the isothermal holding process $[10,16,17,19]$.

It is known that the presence of cementite $(\theta)$, which decreased the carbon supersaturation of the matrix, plays an important role in the reversion kinetics [16]. The distributions of $\theta$ just before reversion were examined by SEM observations at various heating rates, as shown in Figure 4. It was found that a large amount of $\theta$ particles precipitated in all the cases, and a high heating rate led to fine and high number density $\theta$ particles.
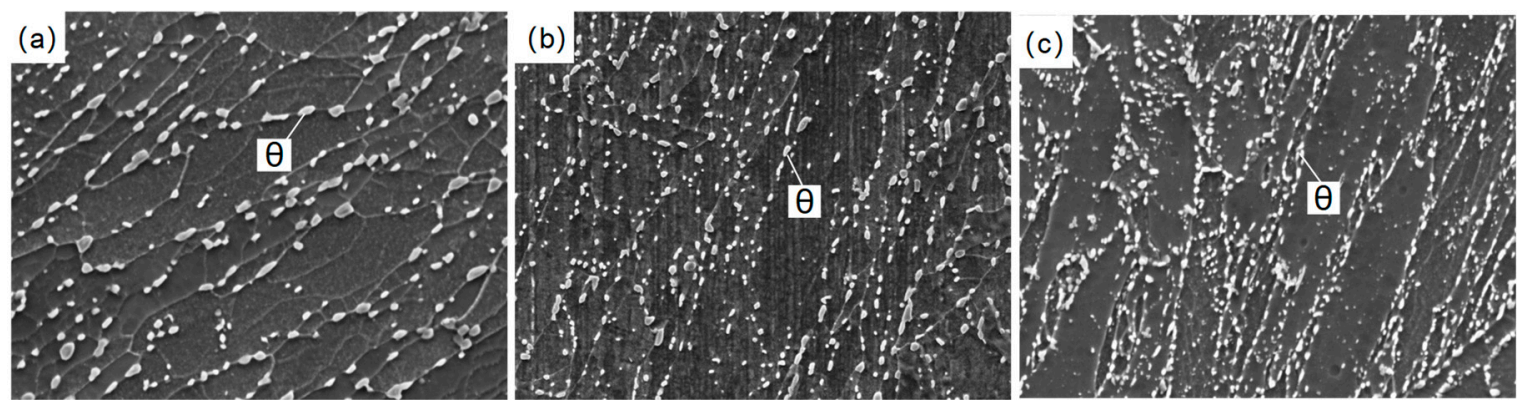

Figure 4. SEM images of the samples heated to $978 \mathrm{~K}$ just before reversion at the heating rate of (a) $0.1 \mathrm{~K} / \mathrm{s}$, (b) $1 \mathrm{~K} / \mathrm{s}$, and (c) $20 \mathrm{~K} / \mathrm{s}$.

The reversion at $1 \mathrm{~K} / \mathrm{s}$ from $983\left(\mathrm{~A}_{\mathrm{c} 1}\right)$ to $1093 \mathrm{~K}$ was simulated, at first, by DICTRA linked to the TCFE7 and MobFe2 databases. The simulation on acicular $\gamma$ was mainly focused due to its regular spatial distribution. One-dimensional growth of $\gamma$ into $\alpha$ with the system size of $0.5 \mu \mathrm{m}$ (approximately half of block width) was assumed, as shown in case A in Figure 5a, because it has been observed that acicular $\gamma$ is mainly nucleated at martensite block boundaries [15]. The initial thickness of $\gamma$ was set to $1 \mathrm{~nm}$. To take the presence of $\theta$ into account, two cases of $B$ and $C$ as shown in Figure 5 a, which correspond to the reversion with $\theta$ dissolution in $\gamma$ and $\alpha$, respectively, were considered.

In this simulation, the initial size and composition of $\theta$ were determined by the volume fraction and composition of $\theta$ under ortho-equilibrium with $\alpha$ just below $\mathrm{A}_{\mathrm{c} 1}$ temperature $\left(X_{\theta}^{\mathrm{Mn}}=9.0\right.$ atom $\left.\%\right)$. Accordingly, the ortho-equilibrium $\alpha$ composition was used as the initial composition for both $\alpha$ and $\gamma$ phases.

The calculated and measured acicular $\gamma$ thicknesses as a function of the temperature are shown in Figure $5 \mathrm{~b}$. The thickness simulated by case A (infinite interface mobility) had an abrupt increase at the beginning, resulting in a much larger value than the measurement. Considering the presence of $\theta$ (cases B and C), the $\gamma$ growth was greatly retarded at low temperatures and close to the measurement. This retardation effect was due to the reduction of the carbon supersaturation in the matrix which was caused by the presence of $\theta$. However, the $\gamma$ growth increased dramatically at high temperatures and exceeded the measurement for both cases. Such a dramatic increase in $\gamma$ thickness was caused by the transition from partitioning to partitionless growth mode of $\gamma$ at a higher temperature and, thus, at a larger driving force. This can be observed in the Mn profiles taken from case $C$, as shown in Figure 5d. At $1033 \mathrm{~K}$, the Mn composition in $\gamma$ was higher than that in $\alpha$ at the interface, indicating 
that macroscopic partitioning of Mn occurred at the interface, namely, that the $\gamma$ growth was in the partitioning growth mode. Meanwhile, at $1043 \mathrm{~K}$, the Mn profile had no significant change after passing the interface, except for a thin spike at the interface where the partitionless growth mode takes place. The similar result was obtained for case B, which will be not shown here. Therefore, the slower growth of acicular $\gamma$ accompanied by Mn partitioning at high temperatures cannot be predicted in those conditions.
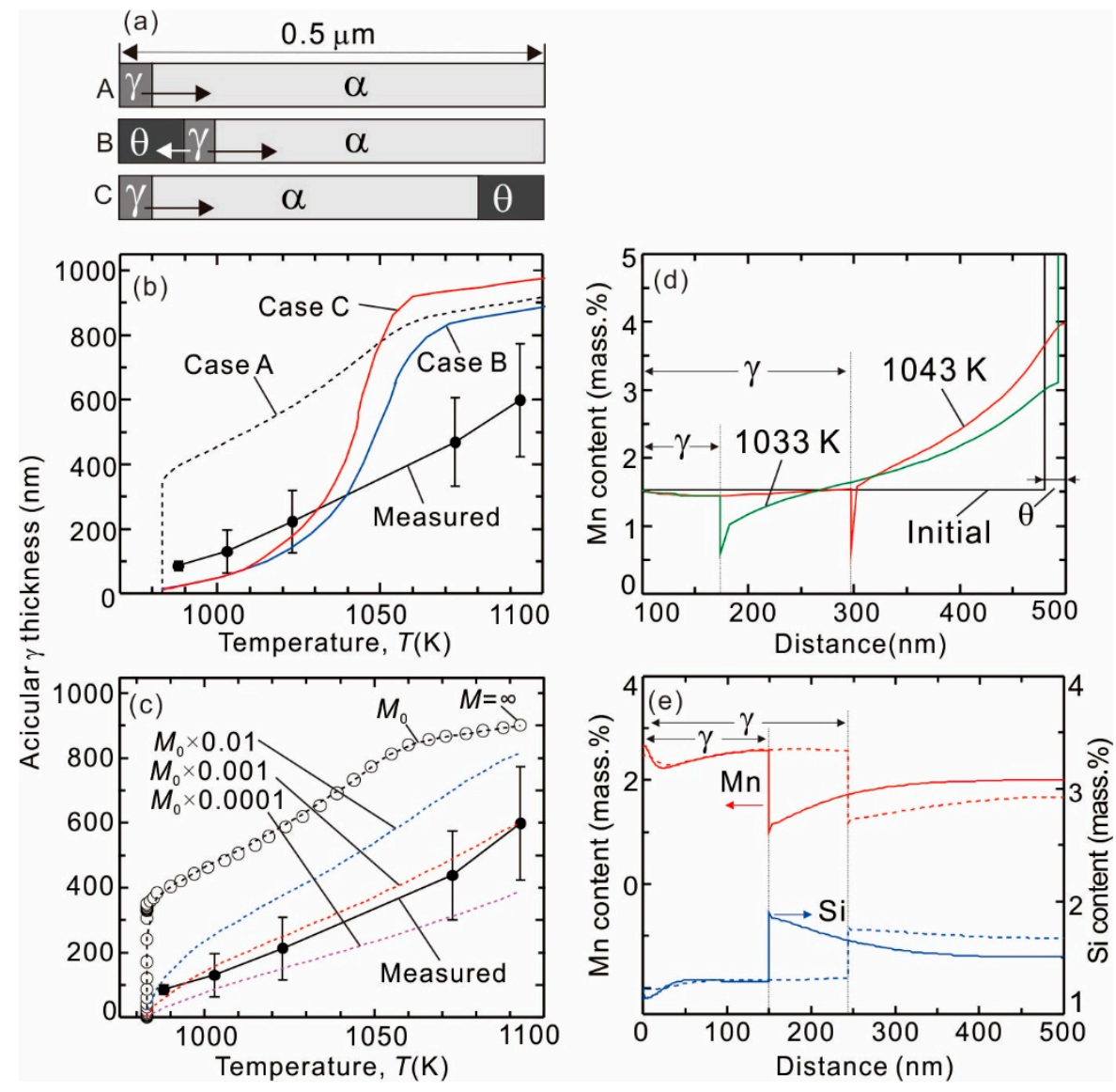

Figure 5. (a) Three different geometries for the simulation of $\gamma$ reversion. Comparisons between measured and simulated thickening kinetics of acicular $\gamma$ in cases (b) A, B, C with infinite interface mobility, and (c) case A with different interface mobilities. (d) Concentration profiles of Mn at different temperatures in case (c). (e) Concentration profiles of Mn and $\mathrm{Si}$ in the early stage of reversion at $1073 \mathrm{~K}$ at interface mobility of $0.001 M_{0}$.

In a previous study [15], it was found that the acicular $\gamma$ holds near-K-S ORs with all the surrounding TM matrix, while the globular $\gamma$ holds non-K-S ORs with most of its surrounding TM matrix. The interface with a K-S OR has better coherency than that without a K-S OR. It is generally considered that an interface with good coherency has a lower intrinsic interface mobility. In the authors' previous work, it was found that [16] finite interface mobility plays an important role in the growth kinetics of acicular $\gamma$ during the isothermal holding process. Finite interface mobility can cause an additional energy dissipation $(\Delta G)$ during the interface migration, which can be expressed by $[16,20]$

$$
\Delta \mathrm{G}=v / M \cdot V_{m}
$$

where $\Delta G$ is the free energy dissipation at the interface for $1 \mathrm{~mol}$ of the substitutional atoms transferred across the interface, $v$ is the velocity of the interface, $M$ is the interface mobility, and $V_{m}$ is the molar volume. 
To take the finite interface mobility into account, the value of acicular $\gamma / \mathrm{TM}$ interface mobility is needed for the DICTRA calculation. Several $\alpha / \gamma$ interface mobilities were reported for fcc $\rightarrow$ bcc massive transformations [21-23]. The massive transformation occurs by migration of incoherent interface; therefore, the mobility of the acicular $\gamma / \mathrm{TM}$ interface with better coherency should be smaller than the reported mobilities. Hence, in this study, in order to reduce the interface mobility, the reported interface mobility [21] $\left(M_{0}=-4 \times 10^{-7} \exp (-140,000 / \mathrm{RT}) \mathrm{m}^{4} / \mathrm{Js}\right)$ was multiplied by various small constants (1 0.001) to evaluate the growth of acicular $\gamma$, as simulated in the isothermal holding process [16].

The calculated result is shown in Figure 5c. Consideration of the interface mobility of $M_{0}$ resulted in a negligibly small difference in reversion kinetics. When the interface mobility was decreased lower than $0.01 M_{0}$, the growth of $\gamma$ was gradually retarded both at low and high temperatures, and the prediction almost coincided with the measurement at $0.001 M_{0}$. The predicted $\gamma$ growth kinetics had no dramatic change with temperature because there was no transition in growth mode when temperature increased. This can be seen from the Mn and Si profiles assuming $0.001 M_{0}$ as shown in Figure $5 \mathrm{e}$, where solid and dotted lines represent profiles at the temperatures of 1033 and $1073 \mathrm{~K}$ (temperature of EPMA measurement), respectively. Mn and Si were clearly partitioned at both high and low temperatures, which was in good agreement with the observations. Therefore, interface mobility is an important factor for the growth of acicular $\gamma$, in addition to $\theta$. This is consistent with the case of the isothermal holding process [16], where multiplication of 0.001 to $M_{0}$ also showed good agreement with variations of acicular $\gamma$ thickness during isothermal annealing at $1023 \mathrm{~K}$.

From the above calculation, it can be seen that at low temperatures, the effect of interface mobility was weak because both the presence of $\theta$ and low interface mobility led to partitioning growth mode. However, at high temperatures, the finite interface mobility became the rate-controlling factor in the growth of acicular $\gamma$. On the other hand, the rapid growth rate at high temperatures for the cases of $B$ and $\mathrm{C}$ in Figure $5 \mathrm{~b}$ may correspond to the growth of globular $\gamma$, whose interface mobility should be larger than that of acicular $\gamma$.

According to the above discussion, it is possible that regardless of whether it was acicular or globular $\gamma$, the growth mode was partitioning at low temperatures and then they may have a similar growth rate and appearance. However, at high temperatures, the driving force for reversion was larger and the growth of globular $\gamma$ became partitionless due to the poor interface coherency with the surrounding TM, which grew much faster than that of the acicular $\gamma$ that is under partitioning mode. According to Figure 1b, a high heating rate promoted the $\gamma$ reversion that occurred at high temperatures. This made the partitionless growth of globular $\gamma$ more easily formed. Therefore, more globular $\gamma$ can be formed at a high heating rate.

In order to understand the low fraction of globular $\gamma$ formed at a low heating rate, the $\gamma$ growth kinetics at a low heating rate of $0.1 \mathrm{~K} / \mathrm{s}$ in the case $\mathrm{C}$ (infinite interface mobility) were calculated and the corresponding result is shown in Figure 6a, in which the growth of $\gamma$ at $1 \mathrm{~K} / \mathrm{s}$ is also plotted for comparison. At low temperatures, the calculated $\gamma$ thickness was larger at a heating rate of $0.1 \mathrm{~K} / \mathrm{s}$ than that at the heating rate of $1 \mathrm{~K} / \mathrm{s}$. However, at high temperatures, the inverse result was obtained. This is similar to the experimental observations shown in Figure $1 \mathrm{~b}$. The element profiles shown in Figure $6 \mathrm{~b}$ reveal that the growth of $\gamma$ at the heating rate of $0.1 \mathrm{~K} / \mathrm{s}$ was always under partitioning growth mode, regardless of the temperature. At low temperatures, Mn was severely enriched into $\gamma$, due to the longer partitioning time at the low heating rate, and the martensite matrix became Mn-depleted. It can be seen from the Mn content profiles that the Mn content in the martensite matrix at $1043 \mathrm{~K}$ at the heating rate of $0.1 \mathrm{~K} / \mathrm{s}$ was much lower than that at the heating rate of $1 \mathrm{~K} / \mathrm{s}$. Mn depletion in the martensite matrix greatly decreased the driving force for reversion, which caused the growth of $\gamma$ under partitioning mode, even at high temperatures. The partitioning growth mode of $\gamma$ suppressed the reversion at high temperatures at the low heating rate, and may have caused the low fraction of globular $\gamma$. 

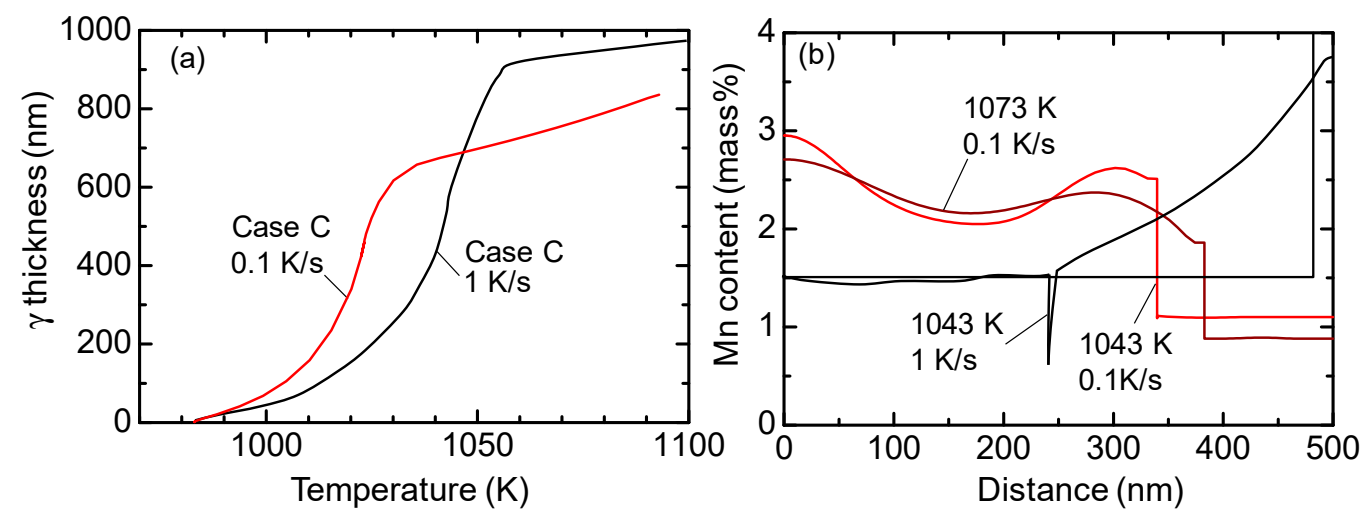

Figure 6. (a) Comparisons between simulated thickening kinetics of $\gamma$ in case $C$ with infinite interface mobility at the heating rates of $1 \mathrm{~K} / \mathrm{s}$ and $0.1 \mathrm{~K} / \mathrm{s}$. (b) Concentration profiles of $\mathrm{Mn}$ at different temperatures in case $\mathrm{C}$ at different heating rates.

It needs to be pointed out that in the above calculation, the same Mn content in $\theta$ is assumed for different heating rates. Indeed, the degrees of pre-tempering before reversion were different and depend on the heating rates, as shown in Figure 4. With a decrease in heating rate, the martensite was more severely tempered. It was reported that heavy pre-tempering leads to severer Mn enrichment into $\theta$ and, thus, suppresses the formation of globular $\gamma$ [14]. Therefore, the longer tempering time before reversion at low heating rates may also contribute to the low fraction of globular $\gamma$ formed at low heating rates. On the other hand, a high number and density of fine $\theta$ particles was formed at a high heating rate, and $\theta$ was proposed to be the nucleation site for globular austenite [15]. Therefore, the higher density of $\theta$ may be partly responsible for more globular $\gamma$ being formed at the faster heating rate.

Moreover, the possibility of the temperature dependence of the nucleation kinetics of acicular and globular $\gamma$ cannot be denied, which may also contribute to the formation of low or high densities of globular $\gamma$ at low or high heating rates, respectively.

\section{Summary}

In summary, the effects of heating rate on reverted $\gamma$ morphology in reversion from martensitic $\mathrm{Fe}-2.02 \mathrm{Mn}-1.49 \mathrm{Si}-0.3 \mathrm{C}$ alloy during a continuous heating process have been studied. It was found that a low heating rate enhanced the formation of acicular austenite, the growth of which was accompanied by Mn partitioning, while a high heating rate favored the formation of globular austenite, the growth of which was partitionless. DICTRA simulation revealed that there was a transition in growth mode from partitioning to partitionless for the globular austenite with an increase in temperature. At the low heating rate, the severer Mn enrichment into austenite caused Mn depletion in the tempered martensite matrix, which decreased the driving force for reversion and caused the austenite to grow under partitioning mode, regardless of the temperature. Meanwhile, high heating rates decreased the degrees of Mn partitioning into the austenite and thus led to a larger driving force for reversion which allowed the austenite to grow through a partitionless mode during heating. This led to an increase in the fraction of globular austenite.

Author Contributions: X.Z. and G.M., conceived and designed the experiments; X.Z. performed the experiments and collected the data; X.Z. and G.M. analyzed the data; X.Z. was responsible for writing-original draft preparation; G.M., Y.T., and T.F. discussed the results and revised the manuscript. T.F. was responsible for supervision and project administration.

Funding: This research was financially supported by the "Technological Development of Innovative New Structural Materials" project through the New Energy and Industrial Technology Development Organization of Japan and by "Nanotechnology Platform" Program of the Ministry of Education, Culture, Sports, Science and Technology, Japan.

Conflicts of Interest: The authors declare no conflict of interest. 


\section{References}

1. Sugimoto, K.; Kanda, A.; Kikuchi, R.; Hashimoto, S.; Kashima, T.; Ikeda, S. Ductility and formability of newly developed high strength low alloy TRIP-aided sheet steels with annealed martensite matrix. ISIJ Int. 2002, 42, 910-915. [CrossRef]

2. Nehrenberg, A.E. Growth of austenite in cold-rolled tempered martensite. Trans. AIME 1952, $194,181$.

3. Sadovskii, V.D. Problems of Physical Metallurgy and Heat Treatment; Mashgiz: Moscow, Russia, 1956; pp. 31-52.

4. Matsuda, S.; Okamura, Y. Reverse transformation of low-carbon low alloy steels. Tetsu-to-Hagane 1974, 60, 226-238. [CrossRef]

5. Plichata, M.R.; Aaronson, H.I. Influence of alloying elements upon the morphology of austenite formed from martensite in Fe-C-X alloys. Metall. Trans. 1974, 5, 2611-2613. [CrossRef]

6. Watanabe, S.; Kunitake, T. On the formation of austenite grains from prior martensitic structure. Tetsu-to-Hagané 1975, 61, 96-106. [CrossRef]

7. Kimmins, S.T.; Gooch, D.J. Austenite memory effect in 1Cr-1Mo-0.75V (Ti, B) steel. Met. Sci. 1983, 17, 519-532. [CrossRef]

8. Hara, T.; Maruyama, N.; Shinohara, Y.; Asahi, H.; Shigesato, G.; Sugiyama, M.; Koseki, T. Abnormal $\alpha$ to $\gamma$ transformation behavior of steels with a martensite and bainite microstructure at a slow reheating rate. ISIJ Int. 2009, 49, 1792-1800. [CrossRef]

9. Nakada, N.; Tsuchiyama, T.; Takaki, S.; Miyano, N. Temperature dependence of austenite nucleation behavior from lath martensite. ISIJ Int. 2011, 51, 299-304. [CrossRef]

10. Luo, H.; Shi, J.; Wang, C.; Cao, W.; Sun, X.; Dong, H. Experimental and numerical analysis on formation of stable austenite during the intercritical annealing of 5Mn steel. Acta Mater. 2011, 59, 4002-4014. [CrossRef]

11. Nakada, N.; Tsuchiyama, T.; Takaki, S.; Hashizume, S. Variant Selection of reversed austenite in lath martensite. ISIJ Int. 2007, 47, 1527-1532. [CrossRef]

12. Nakada, N.; Mizutani, K.; Tsuchiyama, T.; Takaki, S. Difference in transformation behavior between ferrite and austenite formations in medium manganese steel. Acta Mater. 2014, 65, 251-258. [CrossRef]

13. Liu, Z.Q.; Miyamoto, G.; Yang, Z.G.; Furuhara, T. Excess carbon enrichment in austenite during intercritical annealing. Metall. Mater. Trans. A 2013, 44, 4872-4875. [CrossRef]

14. Liu, Z.Q.; Miyamoto, G.; Yang, Z.G.; Zhang, C.; Furuhara, T. Effects of pre-tempering on intercritical annealing in Fe-2Mn-0.3 C Alloy. Metall. Mater. Trans. A 2014, 45, 5290-5294. [CrossRef]

15. Zhang, X.; Miyamoto, G.; Toji, Y.; Nambu, S.; Koseki, T.; Furuhara, T. Orientation of austenite reverted from martensite in Fe-2Mn-1.5Si-0.3C alloy. Acta Mater. 2018, 144, 601-612. [CrossRef]

16. Zhang, X.; Miyamoto, G.; Kaneshita, T.; Yoshida, Y.; Toji, Y.; Furuhara, T. Growth mode of austenite during reversion from martensite in Fe-2Mn-1.5Si-0.3C alloy: A transition in kinetics and morphology. Acta Mater. 2018, 154, 1-13. [CrossRef]

17. Wei, R.; Enomoto, M.; Hadian, R.; Zurob, H.S.; Purdy, G.R. Growth of austenite from as-quenched martensite during intercritical annealing in an Fe-0.1 C-3Mn-1.5 Si alloy. Acta Mater. 2013, 61, 697-707. [CrossRef]

18. DeHoff, R.T. Quantitative metallography; McGraw-Hill: New York, NY, USA, 1968.

19. Ågren, J. Computer-simulations of the austenite ferrite diffusional transformations in low alloyed steels. Acta Metall. 1982, 30, 841-851. [CrossRef]

20. Christian, J.W. The Theory of Transformations in Metals and Alloys, 3rd ed.; Pergamon Press: Oxford, UK, 2002.

21. Krielaart, G.P.; van Der Zwaag, S. Kinetics of $\gamma \rightarrow \alpha$ phase transformation in Fe-Mn alloys containing low manganese. Mater. Sci. Technol. 1998, 14, 10-18. [CrossRef]

22. Wits, J.J.; Kop, T.A.; van Leeuwen, Y.; Sietsma, J.; van Der Zwaag, S. A study on the austenite-to-ferrite phase transformation in binary substitutional iron alloys. Mater. Sci. Eng. A 2000, 283, 234-241. [CrossRef]

23. Gamsjäger, E.; Militzer, M.; Fazeli, F.; Svoboda, J.; Fischer, F. Interface mobility in case of the austenite-to-ferrite phase transformation. Comput. Mater. Sci. 2006, 37, 94-100. [CrossRef]

(C) 2019 by the authors. Licensee MDPI, Basel, Switzerland. This article is an open access article distributed under the terms and conditions of the Creative Commons Attribution (CC BY) license (http:/ / creativecommons.org/licenses/by/4.0/). 